\title{
TTR
}

Traduction, terminologie, re?daction

\section{Dixièmes assises de la traduction littéraire (Arles 1993). Atlas/Actes Sud, 1994, 221 pages.}

\section{Sherry Simon}

Volume 8, numéro 1, 1er semestre 1995

Orientations européennes en traductologie

URI : https://id.erudit.org/iderudit/037208ar

DOI : https://doi.org/10.7202/037208ar

Aller au sommaire du numéro

\section{Éditeur(s)}

Association canadienne de traductologie

ISSN

0835-8443 (imprimé)

1708-2188 (numérique)

Découvrir la revue

Citer ce compte rendu

Simon, S. (1995). Compte rendu de [ Dixièmes assises de la traduction littéraire (Arles 1993). Atlas/Actes Sud, 1994, 221 pages.] TTR, 8(1), 287-288.

https://doi.org/10.7202/037208ar d'utilisation que vous pouvez consulter en ligne.

https://apropos.erudit.org/fr/usagers/politique-dutilisation/ 


\section{Dixièmes assises de la traduction littéraire (Arles 1993). Atlas/Actes Sud, 1994, 221 pages.}

Grâce à la maison d'édition Actes Sud, au Collège international des traducteurs littéraires installé également en Arles, et aux assises annuelles de la traduction littéraire tenues dans cette ville, il s'est créé dans le midi de la France un véritable centre de rayonnement de la traduction littéraire. L'importance de la publication annuelle des Actes de ces assises consiste peut-être moins dans son contenu que dans ce qu'il reflète du prestige grandissant de la traduction littéraire en Europe. Le programme des assises est chaque année impressionnant: présence de conférenciers de grande renommée (cette année Umberto Eco, qui reçoit par la même occasion son bâton de maréchal de la Légion d'honneur des mains de Jacques Toubon, alors ministre de la culture), ateliers de langues d'une diversité vertigineuse (cette année yiddish, estonien, hongrois, provençal, finnois, anglais, espagnol, nééerlandais, turc et albanais), discussions entre auteurs et traducteurs attitrés (les auteurs Breyten Breytenbach, Alfredo Bryce Echenique, Nedim Gursel et Ismail Kadaré ont participé en 1993), et tables rondes permettant enfin aux traducteurs littéraires de se dévoiler comme participants à part entière dans la production de la littérature. 
Les Actes se donnent comme une représentation fidèle des assises et réunissent donc discours d'apparat, résumés d'atelier et discussions qui ne gagnent pas toujours à être reçus hors contexte. En comparaison à d'autres années où des thèmes plus pointus et plus urgents ont été débattus (la traduction de l'arabe, par exemple, ou la traduction controversée des œuvres de Freud), les Actes de 1993 donnent l'impression d'une certaine légèreté. Il faut espérer que les Assises des années à venir, tout en continuant à jouer leur rôle de promotion, restent aussi un stimulant à la réflexion sur la traduction littéraire.

Sherry Simon

Université Concordia 